\title{
ECOLOGICAL SOCIETY OF AMERICA
}

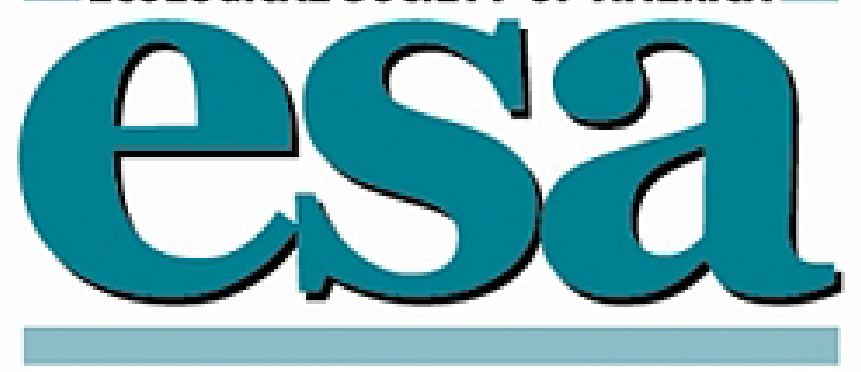

A Reassessment of Using Light-Sensitive Diazo Paper For Measuring Integrated Light in the Field

Author(s): Robert E. Bardon, David W. Countryman and Richard B. Hall

Source: Ecology, Vol. 76, No. 3 (Apr., 1995), pp. 1013-1016

Published by: Ecological Society of America

Stable URL: http://www.jstor.org/stable/1939365

Accessed: 03/07/2014 10:33

Your use of the JSTOR archive indicates your acceptance of the Terms \& Conditions of Use, available at http://www.jstor.org/page/info/about/policies/terms.jsp

JSTOR is a not-for-profit service that helps scholars, researchers, and students discover, use, and build upon a wide range of content in a trusted digital archive. We use information technology and tools to increase productivity and facilitate new forms of scholarship. For more information about JSTOR, please contact support@jstor.org. 
Levins, R. 1968. Evolution in changing environments. Princeton University Press, Princeton, New Jersey, USA.

Mellors, W. R. 1975. Selective predation of ephippial Daphnia and the resistance of ephippial eggs to digestion. Ecology 56:974-980.

Mortimer, C. H. 1935. Untersuchungen über den Generationswechsel der Cladoceren. Naturwissenschaft 23:476480.

Nilssen, J. P. 1977. Cryptic predation and the demographic strategy of two limnetic cyclopoid copepods. Memorie dell'Instituto Italiano di Idrobiologia dott Marco de Marchi 34:187-196.

Pijanowska, J. 1993. Diel vertical migration in zooplankton: fixed or inducible behavior? Archiv für Hydrobiologie 39: $89-97$.

Platt, W. J. 1976. The natural history of a fugitive prairie plant (Mirabilis hirsuta (Pursh) MacM.). Oecologia 22: 399-409.

Schwartz, S. S., and P. D. N. Hebert. 1987. Methods for the activation of the resting eggs of Daphnia. Freshwater Biology 17:373-379.

Sommer, U. 1989. Nutrient status and nutrient competition of phytoplankton in a shallow, hypertrophic lake. Limnology and Oceanography 34:1162-1173.

Stibor, H. 1992. Predator induced life-history shifts in a freshwater cladoceran. Oecologia 92:162-165.

Strickler, J. R., and S. Twombly. 1975. Reynolds number, diapause and predatory copepods. Internationale Vereini- gung für theoretische und angewandte Limnologie, Verhandlungen 19:2943-2950.

Stross, R. G. 1987. Photoperiodism and phased growth in Daphnia populations: coaction in perspective. Memorie dell'Instituto Italian di Idrobiologia dott Marco de Marchi 45:413-437.

Taylor, F. 1980. Optimal switching to diapause in relation to the onset of winter. Theoretical Population Biology 18: 125-133.

Venable, D. L., and J. S. Brown. 1988. The selective interactions of dispersal, dormancy, and seed size as adaptations for reducing risk in variable environments. American Naturalist 131:360-384.

Venable, D. L., and L. Lawlor. 1980. Delayed germination and dispersal in desert annuals: escape in space and time. Oecologia 46:272-282.

Weider, L. J., and J. Pijanowska. 1993. Plasticity of Daphnia life histories in response to chemical cues from predators. Oikos 67:385-392.

Zaffagnini, F. 1987. Reproduction in Daphnia. Memorie dell'Instituto Italiano di Idrobiologia dott Marco de Marchi 45:245-284.

Manuscript received 17 November 1993; revised and accepted 27 September 1994; final version 24 October 1994.
Ecology, 76(3), 1995, pp. 1013-1016

(C) 1995 by the Ecological Society of America

\section{A REASSESSMENT OF USING LIGHT-SENSITIVE DIAZO PAPER FOR MEASURING INTEGRATED LIGHT IN THE FIELD}

\section{Robert E. Bardon, ${ }^{1}$ David W. Countryman, ${ }^{1}$ and Richard B. Hall'}

In 1961, D. T. C. Friend published a simple method that he recommended for measuring integrated light values in the field. The method calibrated light-sensitive diazo paper against a standard light-measuring device. A stack of photosensitive Ozalid paper was exposed for daily periods, and the amount of light energy received was estimated from the number of layers of paper that were bleached after dry development with ammonia vapor. Friend's original work addressed the method for developing diazo paper into a light measuring device and some examples of its use.

\footnotetext{
${ }^{1}$ Department of Forestry, Iowa State University, Ames, Iowa 50011 USA.
}

Since the introduction of this method to the ecological community, many people have used this apparently straightforward, simple technique to provide them with inexpensive, multiple-sample measurements of light in the field. It has been used to measure integrated light under different canopies and as an indicator of leaf area index. The electronic alternatives (e.g., a LI-COR Quantum or Line Sensor) are very expensive, and hence the diazo paper method became popular. The core assumption of this technique is that the number of diazo sheets exposed is a function of the total quantity of radiation seen (i.e., duration $\times$ intensity).

The objective of this study was to determine if the amount of accumulated photosynthetic photon flux density (PPFD) measured with a light meter is highly correlated with the number of exposed sheets of diazo paper under a variety of conditions.

\section{Methods}

Stacks of diazo paper (200SE Ozalid paper made by Film Paper Corporation Company of America) were constructed into booklets containing 20 sheets. The booklets were placed in petri dishes, $35 \times 10 \mathrm{~mm}$, to protect them from moisture. A piece of sponge covered with black paper was placed in each dish so that, when a booklet was placed on top of the sponge and the lid replaced, the sensitive surface of the paper was held 

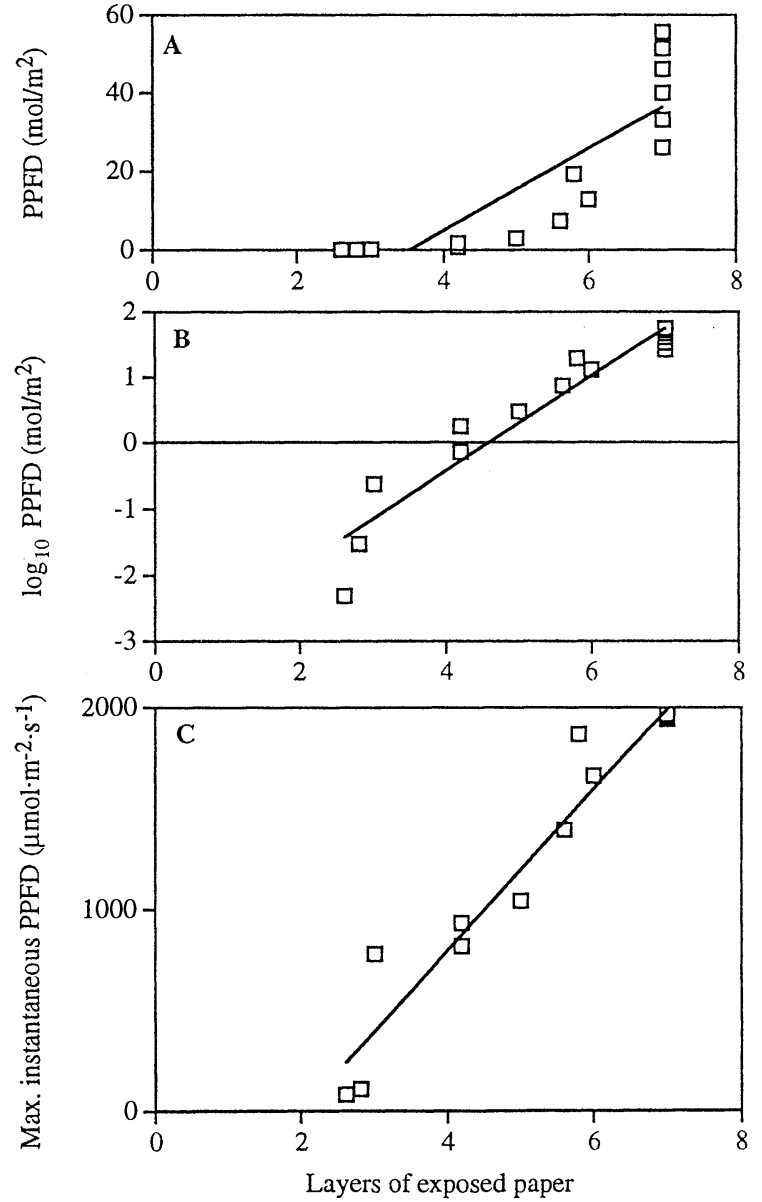

FIG. 1. Data collected on 21 June 1993 resulted in linear relationships. (A) PPFD $\left(\mathrm{mol} / \mathrm{m}^{2}\right)=-36.83+10.47$ (layers of exposed diazo paper $),\left(r^{2}=0.73\right)$. (B) $\log _{10}$ PPFD $\left(\mathrm{mol} / \mathrm{m}^{2}\right)$ $=-3.29+0.72$ (layers of exposed diazo paper), $\left(r^{2}=0.92\right)$. (C) maximum instantaneous PPFD $\left(\mu \mathrm{mol} \cdot \mathrm{m}^{-2} \cdot \mathrm{s}^{-1}\right)=$ $-788.82+397.52$ (layers of exposed diazo paper), $\left(r^{2}=\right.$ $0.94)$.

flat against the inner surface of the lid. A piece of black paper with a central hole of $\approx 0.95 \mathrm{~cm}^{2}$, allowing light to reach the sensitive surface of the booklet, was placed inside the lid. The hole for exposing the paper was covered with black vinyl tape on the outside of the lid until exposure time. The construction of the booklets and the petri dishes was carried out in a photography darkroom and closely followed Friend's (1961) method. Once the booklets and petri dishes were constructed, the petri dishes were stored in a dark, dry place until they were used in the field.

To develop relationships between diazo paper and accumulated and maximum PPFD, 75 petri dishes and a LI-COR 190SA quantum sensor, with a LI-COR 1000 data logger (LI-COR, Lincoln, Nebraska) were placed in full sunlight before 0800 on 21 June 1993. The sky was clear for the entire day. The dishes were protected from full sunlight preceding the exposure time by placing black construction paper over the top of the dishes. All 75 dishes were exposed at 0800 by removing the black construction paper. Exposure was stopped on separate sets of five dishes by sliding the black construction paper back over the top of the dishes at 0801, 0805, 0810, 0820, 0840, 0900, 1000, 1100, 1200, 1300, $1400,1500,1600,1700$, and 1800. As the dishes were removed, black vinyl tape was placed over the exposure hole on the outside of the lid, and the dishes were placed in a light-tight box until they were developed. Integrated PPFD readings were recorded every minute from 0800 to 1800 with the quantum sensor and data logger. The accumulated PPFD was calculated for each time interval that paper samples were exposed.

To observe the rate of diazo paper exposure under constant light conditions, three sets of 36 petri dishes and a LI-COR 190SA quantum sensor with a LI-COR 1000 data logger were placed in a growth chamber. Each set of 36 petri dishes was in place from 0800 until 1600. The first set of 36 petri dishes was exposed to a constant irradiance of $870 \mu \mathrm{mol} \cdot \mathrm{m}^{-2} \cdot \mathrm{s}^{-1}$. The second set of 36 petri dishes was exposed to a constant irradiance of $130 \mu \mathrm{mol} \cdot \mathrm{m}^{-2} \cdot \mathrm{s}^{-1}$. And the third set of 36 petri dishes was exposed to a combination of two irradiances, $870 \mu \mathrm{mol} \cdot \mathrm{m}^{-2} \cdot \mathrm{s}^{-1}$ from 0800 until 0930 and $130 \mu \mathrm{mol} \cdot \mathrm{m}^{-2} \cdot \mathrm{s}^{-1}$ from 0930 until 1600 . The dishes were protected from light before their exposure time by placing black construction paper over the top of the dishes. Exposure was stopped on separate sets of three dishes by sliding black construction paper back over the top of the dishes at 0801, 0805, 0810, 0820, 0840, 0900, 0930, 1000, 1100, 1230, 1400, and 1600. Light readings were recorded with the quantum sensor every minute from 0800 to 1600 to verify the light level.

The booklets of diazo paper were developed within $48 \mathrm{~h}$ of exposure to light by treating them with ammonia vapor in a plastic crisper (Friend 1961). In a room with low light levels, the booklets were placed in a wire basket suspended $\approx 2.5 \mathrm{~cm}$ above the surface of $\approx 390 \mathrm{~mL}$ of concentrated ammonia hydroxide, which was added to the plastic crisper. Development time was 20-25 min. The number of layers in the booklet affected by light was determined by counting the number of bleached layers.

Simple linear regression (SAS 1988) was used to develop linear relationships between the number of layers of exposed diazo paper and PPFD $\left(\mathrm{mol} / \mathrm{m}^{2}\right)$, $\log _{10}$ of PPFD, and maximum instantaneous PPFD $\left(\mu \mathrm{mol} \cdot \mathrm{m}^{-2} \cdot \mathrm{s}^{-1}\right)$.

\section{Results and Discussion}

There was a poor linear correlation between the number of layers of exposed diazo paper and PPFD ( $r^{2}$ of 


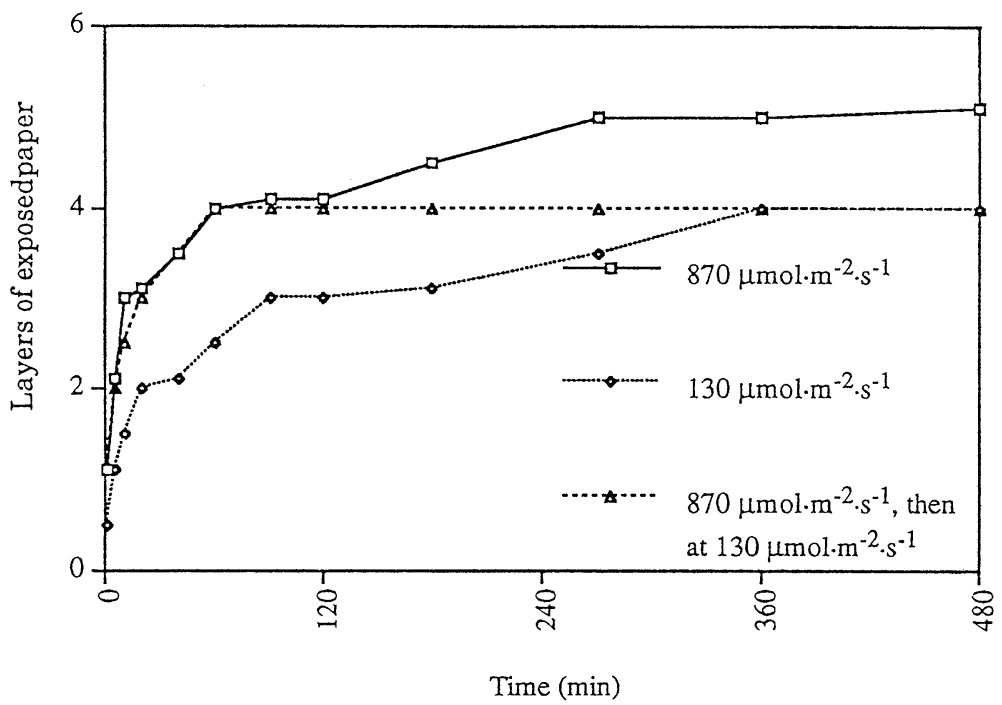

FIG. 2. The number of layers of exposed paper at constant irradiance of $870 \mu \mathrm{mol} \cdot \mathrm{m}^{-2} \cdot \mathrm{s}^{-1}, 130 \mu \mathrm{mol} \cdot \mathrm{m}^{-2} \cdot \mathrm{s}^{-1}$, and at a combination of $870 \mu \mathrm{mol} \cdot \mathrm{m}^{-2} \cdot \mathrm{s}^{-1}(90 \mathrm{~min})$ and $130 \mu \mathrm{mol} \cdot \mathrm{m}^{-2} \cdot \mathrm{s}^{-1}$.

$0.73, P<0.0001$, Fig. 1A). Initially, small changes in PPFD resulted in large changes in the number of exposed sheets. Finally, a large change in PPFD resulted in the exposure of no additional layers of diazo paper. This later point was reached about noon and corresponded to the point of maximum PPFD.

To compare with Friend's (1961) findings, $\log _{10}$ transformation was performed on the PPFD data. The linear relationship between the number of layers of exposed diazo paper and $\log _{10}$ of PPFD (Fig. 1B) had an $r^{2}$ of $0.92, P<0.0001$, which is consistent with previous research (Friend 1961, Del Rio and Berg 1979, Steng et al. 1989, Oliver and Dolph 1992), and would seem to indicate that the diazo paper technique is a good predictor of accumulated PPFD.

Further investigations were conducted to verify if Friend's method of using diazo paper ". . . is suitable for measuring integrated values of light energy under field conditions." (Friend 1961: 580). A linear relationship was developed between the number of exposed layers of diazo paper and maximum instantaneous PPFD $\left(\mu \mathrm{mol} \cdot \mathrm{m}^{-2} \cdot \mathrm{s}^{-1}\right)$ (Fig. 1C). An $r^{2}$ of $0.94, P<$ 0.0001 indicates that a stronger relationship exists between the number of layers of exposed diazo paper and maximum instantaneous PPFD than between the number of layers of exposed diazo paper and accumulated PPFD $\left(r^{2}=0.73\right)$ or $\log _{10}$ of accumulated PPFD $\left(r^{2}=\right.$ 0.92).

An experiment conducted under controlled light conditions within a growth chamber suggests that the diazo paper is not measuring accumulated PPFD (Fig. 2). The diazo paper seems to measure accumulated PPFD under constant irradiance $\left(\approx 870 \mu \mathrm{mol} \cdot \mathrm{m}^{-2} \cdot \mathrm{s}^{-1}\right.$ and $130 \mu \mathrm{mol} \cdot \mathrm{m}^{-2} \cdot \mathrm{s}^{-1}$ ) because the number of exposed layers of paper continued to increase with time. However, when the instantaneous PPFD was held at 870 $\mu \mathrm{mol} \cdot \mathrm{m}^{-2} \cdot \mathrm{s}^{-1}$ for the first $90 \mathrm{~min}$ and then reduced to $130 \mu \mathrm{mol} \cdot \mathrm{m}^{-2} \cdot \mathrm{s}^{-1}$ from 90 to $480 \mathrm{~min}$, the number of layers of exposed paper remained constant after the irradiance was reduced. This is consistent with the field observations of no additional layers of diazo paper being exposed after maximum irradiance was reached. If the diazo paper measured accumulated PPFD, then it would continue to have increased layers of exposed paper even though the irradiance had been reduced. The diazo paper seems to record irradiance at a slow rate, giving the impression that it is recording accumulated PPFD.

\section{Conclusion}

An inexpensive method of using diazo paper (200SE Ozalid paper) to measure accumulated PPFD was tested and a linear relationship was found consistent with previous research (Friend 1961, Del Rio and Berg 1979, Streng et al. 1989, Oliver and Dolph 1992). But further investigation shows that a stronger linear relationship exists between the number of layers of exposed diazo paper and maximum instantaneous PPFD than exists between the number of layers of exposed diazo paper and accumulated PPFD or $\log _{10}$ of accumulated PPFD. Under field conditions, being in full sunlight resulted in exposure of no additional layers of diazo paper after about noon. Diazo paper seems to record irradiance at a slow rate, giving the impression that it is recording accumulated PPFD. Thus, diazo paper should not be used to measure ac- 
cumulated PPFD under field conditions, especially for periods that include a significant amount of time after noon or under conditions with light flecks or varying irradiance.

The diazo technique is far more sensitive to a pulse of maximum radiation (i.e., the maximum intensity) than the total radiation received. Because maximum: are highly correlated with daily or integrated totals, in both open and shaded environments, results using diazo paper have largely gone unchallenged. The results of this paper provide us with a firmer understanding of this technique and, therefore, some potentially important limitations.

Acknowledgments: Journal Paper Number J-15894 of the Iowa Agriculture and Home Economics Experiment Station, Ames, Iowa, Project Number 2172.

\section{Literature Cited}

Del Rio, E., and A. Berg. 1979. Specific leaf area of douglasfir reproduction as affected by light and needle age. Forest Science 25(1):183-186.

Friend, D. T. C. 1961. A simple method of measuring integrated light values in the field. Ecology 42:577-580.

Oliver, W. W., and K. L. Dolph. 1992. Mixed-conifer seedling growth varies. in response to overstory release. Forest Ecology and Management 48:179-183.

SAS. 1988. SAS/STAT user's guide, Release 6.03 Edition. SAS Institute, Cary, North Carolina, USA.

Streng, D. R., J. S. Glitzenstein, and P. A. Harcombe. 1989. Woody seedlings dynamics in an east Texas floodplain forest. Ecological Monographs 59:177-204.

Manuscript received 12 May 1994; revised 13 October 1994; accepted 14 October 1994. 